\title{
Dengue Virus Type 3 in Rio de Janeiro, Brazil
}

\section{Rita Maria R Nogueira/ ${ }^{+}$, Marize P Miagostovich, Ana Maria B de Filippis, Maria Aparecida S Pereira*, Hermann G Schatzmayr}

\author{
Departamento de Virologia, Instituto Oswaldo Cruz-Fiocruz, Av. Brasil 4365, 21045-900 Rio de Janeiro, \\ RJ, Brasil *Secretaria de Saúde de Nova Iguaçu, RJ, Brasil
}

\begin{abstract}
Dengue virus type 3 was isolated for the first time in the country as an indigenous case from a 40 year-old woman presenting signs and symptoms of a classical dengue fever in the municipality of Nova Iguaçu, State of Rio de Janeiro. This serotype has been associated with dengue haemorrhagic epidemics and the information could be used to implement appropriate prevention and control measures. Virological surveillance was essential in order to detected this new serotype.
\end{abstract}

Key words: dengue virus type 3 - virological surveillance - Brazil

Dengue fever (DF) and dengue hemorrhagic fever/dengue shock syndrome (DHF/DSS) are considered the most medically important and widespread mosquito-borne viral diseases. Dengue (DEN) viruses belong to the family Flaviviridae, genus Flavivirus, and occur as four antigenically related but distinct serotypes designated DEN-1, 2, 3 and 4 (Westaway et al. 1985). Although all dengue serotypes are responsible for both DF or DHF/DSS, dengue subtyping methods have been used for epidemiologic and pathogenesis investigations, since genetic differences could reveal important information related to the disease (Lanciotti et al. 1994, Rico-Hesse et al. 1997).

In Brazil, since 1986 dengue epidemics have been occurring annually, becoming a national public health problem. A total of 1,832,371 cases were reported, resulting from DEN-1 and/or DEN2 epidemics, and occurred in 24 out of 26 states and the Federal District/Brasília (Ministry of Health, Brazil). Molecular analysis performed on genome fragments from DEN-1 and DEN-2 viruses identified the Caribbean and Jamaican genotypes, respectively, as the virus strains circulating in the country (Rico-Hesse 1990, Vorndam et al. 1994, Miagostovich et al. 1998). The Jamaica genotype

\footnotetext{
This work was supported by grants from Conselho Nacional de Desenvolvimento Científico e Tecnológico (CNPq) and Oswaldo Cruz Foundation. RMRN, MPM and HGS were supported by a fellowship from CNPq. ${ }^{+}$Corresponding author. Fax: +55-21-642.8909. E-mail: rita@gene.dbbm.fiocruz.br

Received 5 April 2001

Accepted 30 May 2001
}

introduction into the Americas resulted in both an increase in the severe forms of the disease and epidemics in which there were a significant number of DHF/DSS cases (Nogueira et al. 1993, RicoHesse et al. 1997) .

In January 2001, during a virological surveillance carried out in the municipality of Nova Iguaçu, DEN-3 was isolated from a 40 year-old woman presenting signs and symptoms of a classical DF (WHO 1986). This municipality is located $25 \mathrm{~km}$ away from Rio de Janeiro downtown in greater Rio and was the same municipality where DEN-1 was first isolated in 1986 (Schatzmayr et al. 1986). Nova Iguaçu has reported subsequent epidemics of DF, having DEN-1 and DEN-2 viruses isolated during the summer 2000-2001.

DEN-3 virus isolation was performed by inoculation of serum sample into clone C6/36 Aedes albopictus cell line and typed by the indirected fluorescent antibody test using serotype-specific monoclonal antibodies (Gubler et al. 1984). Viral RNAs were extracted from the supernatants of infected cells and from sera using a QIAamp Viral Mini Kit (Qiagen, Inc., Valencia, CA) according to the manufacturer's protocol. The nested RT-PCR (Lanciotti et al. 1992) detected DEN-3 directly from serum sample and confirmed DEN-3 from tissue culture fluid (Figure).

Serological results showed IgM seroconversion by IgM capture enzyme-linked immunosorbent assay (Kuno et al. 1987) while G-ELISA (Miagostovich et al. 1999) characterized dengue primary infection showing titers of $<40$ and $1 / 2560$ on the acute and convalescent serum, respectively.

The above-mentioned data demonstrate the importance of on-going monitoring of samples of DEN viruses circulating in the country in order to 


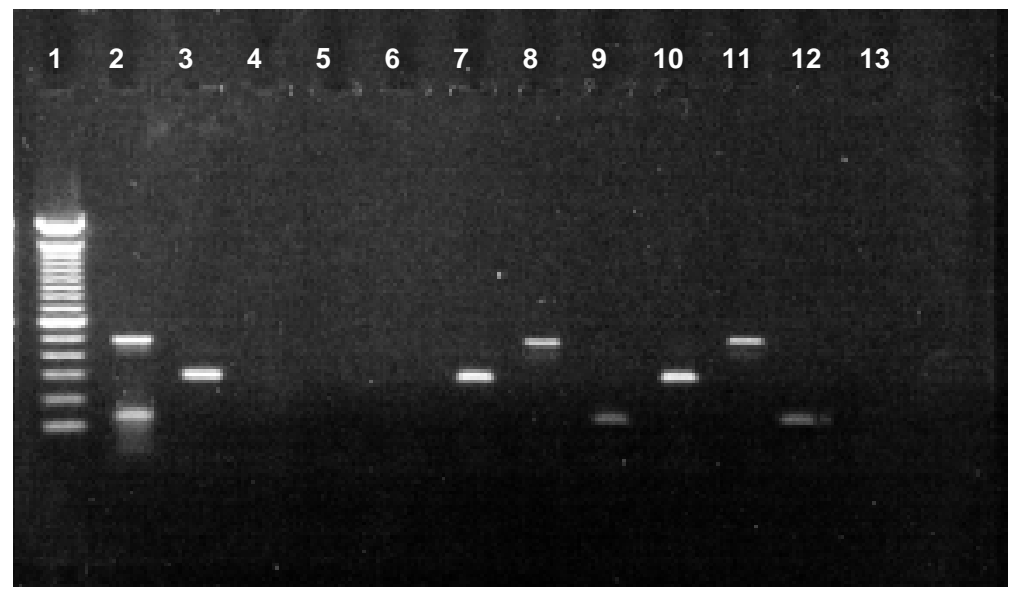

Characterization of DEN-3 virus by reverse transcriptase-polymerase chain reaction (RT-PCR). Ethidium bromide $1 \%$ stained agarose gel showing RT-PCR nested products: lane 1, 100-bp ladder (Gibco); lane 2 molecular wheight marker of DEN-1 and DEN-2 RT-PCR products corresponding to $482 \mathrm{bp}$ and $119 \mathrm{bp}$, respectively; lanes 3 and 7, DEN-3 from fluid culture of Aedes albopictus clone C6/36 infected with serum sample and serum sample from the same patient, respectively; lanes 4, 5 and 6 negative sera; lanes 8 and 9, DEN-1 and DEN-2 from sera; lanes 10,11 and 12 positive controls of DEN-3, DEN-1 and DEN-2; lane 13 water

identify the entry of a new serotype or genotype and a potential association between genotype and virulence. The introduction of this new DEN serotype, with a possibility of a large outbreak may represent a new threath, since DEN-3 virus has been associated with the dengue haemorrhagic occurred in India, Sri Lanka and Central America (Lanciotti et al. 1994, Anonymus 1995).

Three more DEN-3 viruses were isolated afterwards in the State of Rio de Janeiro, two of them in the same area of the first isolated strain.

\section{ACKNOWLEDGMENTS}

To Dr Ari Carvalho de Miranda for encouragement. To Janete Mariotte Lima, Health Department, municipality of Nova Iguaçu. To Eliane Saraiva Machado de Araújo, José da Costa Farias Filho and to José de Carvalho Filho for tecnhical support.

\section{REFERENCES}

Anonymus 1995. Dengue 3 in Central America. Dengue Branch, San Juan, Puerto Rico. Division of Vector-Borne Infectious Diseases. Dengue surveillance 70: $1-4$.

Gubler DJ, Kuno G, Sather E, Valez M, Olivre A 1984. Mosquito cell cultures and specific monoclonal antibodies in surveillance for dengue viruses. $\mathrm{Am} J$ Trop Med Hyg 33: 158-165.

Kuno G, Gomez I, Gubler DJ 1987. Detecting artificial anti-dengue IgM immune complexes using an enzyme-linked immunosorbent assay. Am J Trop Med Hyg 36: 153-159.

Lanciotti RS, Calisher CH, Gubler DJ, Chang G-J, Vorndam V 1992. Rapid detection and typing of dengue viruses from clinical samples by using reverse transcriptase-polymerase chain reaction. JClin
Microbiol 30: 545-551.

Lanciotti RS, Lewis JG, Gubler DJ, Trent DW 1994. Molecular evolution and epidemiology of dengue-3 viruses. J Gen Virol 75: 65-75.

Miagostovich MP, Nogueira RMR, Schatzmayr HG, Lanciotti RS 1998. Molecular epidemiology of Den2 virus in Brazil. Mem Inst Oswaldo Cruz 93: 625626.

Miagostovich MP, Vorndam V, Araújo ESM, Santos FB, Schatzmayr HG, Nogueira RMR 1999. Evaluation of IgG enzyme-linked immunosorbent assay for dengue diagnosis. J Clin Virol 14: 183-189.

Nogueira RMR, Miagostovich MP, Lampe E, Souza RW, Zagne SMO, Schatzmayr HG 1993. Dengue epidemic in the State of Rio de Janeiro, Brazil, 19901991: co-circulation of dengue 1 and dengue 2. Epidemiol Infect 111: 163-170.

Rico-Hesse R 1990. Molecular evolution and distribution of dengue viruses type 1 and 2 in nature. Virology 174: 479-493.

Rico-Hesse R, Harrison LM, Salas RA, Tovar D, Nisalak A, Ramos C, Boshell J, De Mesa MTR, Nogueira RMR, Travassos da Rosa A 1997. Origins of dengue type 2 viruses associated with increased pathogenicity in the Americas. Virology 230: 244-251.

Schatzmayr HG, Nogueira RMR, Rosa APAT 1986. An outbreak of dengue virus at Rio de Janeiro. Mem Inst Oswaldo Cruz, 81: 245-246.

Vorndam V, Nogueira RMR, Trent DW 1994. Restriction enzyme analysis of American region dengue viruses. Arch Virol 136: 191-196.

Westaway EG, Brinton MA, Gaidamovich SY, Horzinek MC, Igarashi A, Kaariainen L, Lvov DK, Porterfield JE, Russell PK, Trent DW 1985. Flaviviridae. Intervirology 24: 183-192.

WHO 1986. Dengue haemorrhagic fever: diagnosis, treatment and control, World Health Organization, Geneve. 